\title{
Fire-Risk Assessment in Northern Greece Using a Modified Fosberg Fire-Weather Index That Includes Forest Coverage
}

\author{
Harry D. Kambezidis ${ }^{1}$ and George K. Kalliampakos ${ }^{2,3}$ \\ ${ }^{1}$ National Observatory of Athens, Institute for Environmental Research and Sustainable Development, \\ Atmospheric Research Team, Lofos Nymphon, 11810 Athens, Greece \\ ${ }^{2}$ National Observatory of Athens, Directorate of Administration, Lofos Nymphon, 11810 Athens, Greece \\ ${ }^{3}$ The Hellenic Parliament, Vassilissis Sofias 2, 10021 Athens, Greece \\ Correspondence should be addressed to Harry D. Kambezidis; harry@noa.gr
}

Received 17 March 2016; Accepted 28 April 2016

Academic Editor: Panagiotis Nastos

Copyright (c) 2016 H. D. Kambezidis and G. K. Kalliampakos. This is an open access article distributed under the Creative Commons Attribution License, which permits unrestricted use, distribution, and reproduction in any medium, provided the original work is properly cited.

\begin{abstract}
The spatial distribution of the monthly mean values for various climatological parameters in Northern Greece is derived. The corresponding data come from measurements at several meteorological stations located in Central Macedonia, Eastern Macedonia, and Thrace (CM/EMT) area in the period 1975-1997. The collected data concern high temperature and low relative humidity, as well as local forest coverage, and are utilized for the calculation of a modified Fosberg Fire-Weather Index in order to estimate the fire risk over Northern Greece due to the local weather under critical conditions. As a result, monthly fire-risk maps of the $\mathrm{CM} / \mathrm{EMT}$ area for the months of May to October are derived for the first time by applying sophisticated analytical geospatial tools and methods. Furthermore, fire events corresponding to the same region and period are added to the derived maps for comparison and for a better evaluation of the method. The resulting correspondence of the predicted fire risk to the local wind-speed behavior and forest abundance demonstrates the need of the necessary precaution measures to limit the future danger levels from fire events.
\end{abstract}

\section{Introduction}

Climate change is a worldwide phenomenon with severe impact to human societies, as it is responsible for many natural hazards. Climate change in conjunction with environmental protection dictates the necessity for comprehensive actions and enhanced research activities in environmental issues [1-3]. Climatological maps are very promising scientific tools in the reconstruction of long-term environmental conditions occurring at different geographical areas; such maps can help local authorities to issue appropriate environmental policies (e.g., [4]). In the past, many research efforts for studying the climatic conditions in Greece have been made, but they were either focusing on a single site (e.g., Athens in $[5,6]$ ) or investigating a single climatological parameter at a time (e.g., temperature in [7-9], precipitation in [10-12]). In this work, fire-risk maps related to temperature, relative humidity, wind speed, and forest coverage are generated for the first time for Central Macedonia, Eastern Macedonia, and Thrace (CM/EMT), a geographic area of $32,968 \mathrm{~km}^{2}$ in the northern part of Greece, belonging to the Climatic Zone C in the country (according to [13]).

Greece's climate is predominantly Mediterranean, having cool winters and hot and dry summers. Furthermore, $\mathrm{CM} / \mathrm{EMT}$ is a region with high forest coverage at $53 \%$, the highest in Greece. The combination of these two parameters leads to a high potential danger for fire in CM/EMT area, especially in the warmest and driest months of the year, that is, May to October. In general, ignition of a fire is related to both the prevailing atmospheric conditions and the local geomorphological structure, among any other anthropogenic factors that are not easily quantified and are excluded from this work (proximity to roads, industrial activities, etc.). For the estimation of the risk of fire there exist in the literature many indices with associated fire-risk scales, from which the most commonly used are the Canadian Fire-Weather Index 
TABLE 1: The meteorological stations network of HNMS in the CM/EMT region with their corresponding forest coverage (in \%).

\begin{tabular}{|c|c|c|c|c|c|c|}
\hline Prefecture & $\begin{array}{c}\text { Forest } \\
\text { coverage } \\
(\%)\end{array}$ & $\begin{array}{c}\text { Location of } \\
\text { meteorological } \\
\text { station }\end{array}$ & Station ID & Longitude (deg) & Latitude (deg) & Elevation (m) \\
\hline Evros & 39.6 & Alexandroupoli & E1 & 25.93 & 40.85 & 3.5 \\
\hline Rodopi & 54.2 & Komotini & E2 & 25.4 & 41.11 & 31 \\
\hline Evros & 39.6 & Orestiada & E3 & 26.52 & 41.52 & 43 \\
\hline Xanthi & 71.8 & Xanthi & $\mathrm{E} 4$ & 24.9 & 41.12 & 43 \\
\hline Thessaloniki & 35.7 & Thessaloniki & E5 & 22.96 & 40.51 & 2 \\
\hline Drama & 76.2 & Drama & E6 & 24.15 & 41.15 & 104 \\
\hline Pella & 53.7 & Edessa & E7 & 22.05 & 40.8 & 237 \\
\hline Kavala & 68.6 & Kavala & E8 & 24.42 & 40.95 & 5 \\
\hline Kavala & 68.6 & Chrysoupoli & E9 & 24.6 & 40.9 & 5 \\
\hline Serres & 42.8 & Serres & E10 & 23.57 & 41.08 & 34 \\
\hline Chalkidiki + Agio Oros & 72.5 & Polygyros & E11 & 23.43 & 40.38 & 545 \\
\hline Imathia & 40.9 & Trikala & E12 & 22.55 & 40.6 & 6 \\
\hline
\end{tabular}

[14-17], the McArthur Forest Fire-Danger Index [15, 18, 19], and the Fosberg Fire-Weather Index [16, 19-21].

In this work, we use the Fosberg Fire-Weather Index (FFWI) introduced by Fosberg [22] to assess the potential danger of fire over CM/EMT due to the weather influence. The use of FFWI has been preferred in this work to any other index for the following reasons:

(i) The FFWI has a very simple form comparing to other indices, since it depends only on temperature, relative humidity, and wind speed.

(ii) Its results have shown to be accurate in most cases for the discrimination of the fire-danger level [16, 23, 24].

(iii) Due to technical limitations, there is no information available about parameters such as the drought factor or the fuel availability, which are required for other indices, since the corresponding meteorological stations do not provide such data.

In order to include in the FFWI a higher impact from fire outbreak related to the prevailing atmospheric conditions, we used the reduced FFWI (rFFWI), which depends on the maximum air temperature and minimum relative humidity instead of their average daily values in the original FFWI. Furthermore, by connecting the rFFWI to the forest coverage of an area such as CM/EMT, we induced the modified reduced FFWI (mrFFWI). The mrFFWI gives the risk-offire as FFWI does, but it uses daily max and min values of air temperature and relative humidity, respectively, and is also connected to the forest coverage of the area where the mrFFWI is applied. The forest coverage of the area is given as an index, that is, the ratio of the area covered by forest to the total one.

By applying the Kriging geostatistical analysis to the calculated mrFFWI values at the selected locations, corresponding maps are generated for the whole CM/EMT area. To compare the predicted fire-danger values with real fire events, the mrFFWI maps also use fire events obtained from the National Forest Agency (NFA) for the years 1984-1997, which have broken out in the CM/EMT area during the months of May to October. These fire events are presented in the mrFFWI maps as points of variable size to reflect the corresponding burned area and thus serving as an evaluation indicator of the method applied in this work.

The classification of most fire-danger indices is divided into 5 categories, that is, low, moderate, high, very high, and extreme (e.g., [25]). The Fosberg index varies between 0 (no danger) and 100 (extreme danger), while any index value above 100 is set to 100 . In this work, the mrFFWI rating is applied after Goodrick [26], where the fire-danger level, including the local forest coverage, is set to low for index values up to 20 , moderate for index values between 20 and 40 , and severe (high, very high, or extreme danger of fire) for index values above 40 .

\section{Materials and Methods}

The necessary climatological data for this work were collected from 12 meteorological stations of the Hellenic National Meteorological Service (HNMS) network located near the major cities of the CM/EMT area; these are given in Table 1 with ID numbers from \#E1 to \#E12 and are presented in Figure 1. For each station, daily data of temperature $(T)$ and relative humidity $(\mathrm{RH})$ and monthly data of wind speed (WS) for the months of May to October were obtained from HNMS in the period 1975-1997. For the missing data, the Kriging geostatistical analysis was used to fill the gaps and produce full datasets for the whole area.

The Kriging/Cokriging methodology [27], which has been applied in the present work through the ARCGIS 10 software, is an advanced geostatistical tool that generates an estimated surface from a scattered set of points. The procedure assumes that the distance or direction between sample points reflects a spatial correlation that can be used 


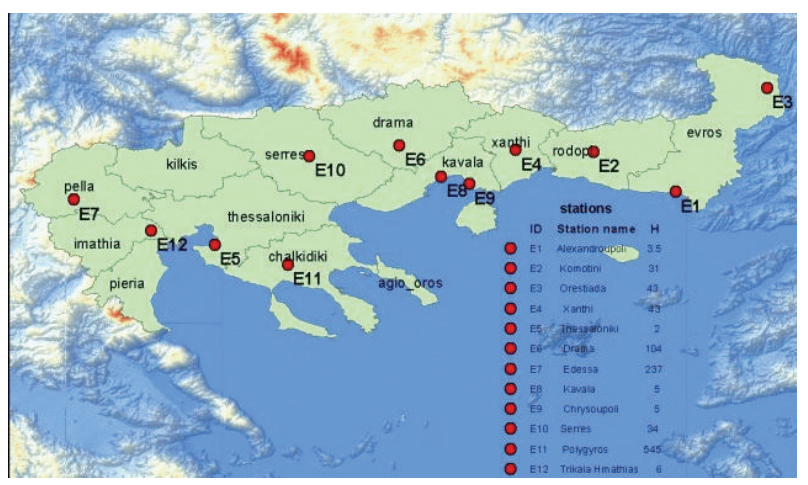

FIgURE 1: The meteorological stations network of HNMS, as they are distributed among the Prefectures of the CM/EMT area, given by their ID numbers referred to in Table 1 .

to explain the variation in the surface. The Kriging tool fits a mathematical function to a specified number of points, or all points within a specified radius, to determine the output value for each location. As a result, the Kriging method gives optimal and unbiased estimates.

In the next step, the daily data were used to calculate monthly mean values of maximum temperature and minimum relative humidity, resulting in the calculation of the rFFWI for each station location. The FFWI is a nonlinear filter of meteorological data designed to provide a simple, linear relationship between the combined weather inputs and wildland fire behavior. Fosberg [22] used only temperature, relative humidity, and wind speed to derive FFWI, with the assumption that the fuel-bed properties such as surface area to volume ratio and moisture of extinction are fixed in both space and time. Incorporating characteristics of the fuel (vegetation) is needed to further develop this index into a true fire-danger index $[23,26]$. The mathematical expression of FFWI is

$$
\text { FFWI }=\sqrt{1+\mathrm{WS}^{2}} \frac{1-2 a+1.5 a^{2}-0.5 a^{3}}{0.3002}
$$

where $a=m / 30$ and

$$
\begin{gathered}
m=0.03229+0.281073 \mathrm{RH}-0.000578 \mathrm{RH} * T \\
\mathrm{RH} \leq 10 \%, \\
m=2.22749+0.160107 \mathrm{RH}-0.01478 \mathrm{~T} \\
10 \%<\mathrm{RH} \leq 50 \%, \\
m=21.0606+0.005565 \mathrm{RH}^{2}-0.00035 \mathrm{RH} * T \\
-0.483199 \mathrm{RH} \quad 50 \%<\mathrm{RH} .
\end{gathered}
$$

In this expression, the variable $a$ represents the ratio of equilibrium moisture content to moisture of extinction of 30 . The numerator of the fraction is called the moisture damping coefficient. The normalized equilibrium moisture content, $a$, is determined from dry-bulb temperature, $T$ (degrees Fahrenheit), and relative humidity, RH (\%), while WS is the wind speed (statute $\mathrm{mph}$ ). The temperature dependence of
FFWI is almost negligible [21], while much stronger variations in the FFWI occur due to WS and $\mathrm{RH}$ variations. As might be expected the FFWI increases strongly with increasing wind speed and decreasing relative humidity. Basically, times of potentially higher fire danger (as described by the above simplified FFWI) are during windy, relatively dry, and, to a lesser extent, warm conditions. Thus, in order to take into consideration in this work the maximum impact of the climatological parameters on FFWI and, therefore, on the expected fire risk for the CM/EMT area, we calculated the rFFWI by using the average maximum temperature $\left(T_{\max }\right)$ and average minimum relative humidity $\left(\mathrm{RH}_{\text {min }}\right)$ values from the corresponding data; the average maximum WS values could not be determined, since wind-speed data were available only as monthly average values, while wind gust data were not available.

These index values were then multiplied by the forestcoverage factor, which varies from 1 (Thessaloniki, \#E5) to 2.13 (Drama, \#E6), giving the mrFFWI. The forest-coverage factor has been calculated by considering the smallest forest coverage in the whole CM/EMT region (see Table 1) as unity (Thessaloniki Prefecture), by adjusting all other values to that and by assigning the meteorological stations to the CM/EMT area they belong to. By including the forest coverage factor in the rFFWI to calculate the mrFFWI, we took into consideration the probability of fire ignition for any given rFFWI values, which have a linear dependence with the forest coverage area. Finally, by using again the Kriging method, maps of the monthly mrFFWI were deduced, resulting in the corresponding monthly risk-offire maps for CM/EMT; these maps are closer to the real environmental conditions responsible for fire ignition. To support this, real-fire events observed in the CM/EMT area for the period May to October 1984-1997 taken from NFA were included in the mrFFWI maps in order to investigate the relationship between the Fosberg index and the distribution of fire incidents over CM/EMT. For deriving these maps, the complementary Cokriging method was utilized for a more accurate description of the corresponding patterns within the geographical area of CM/EMT. The relatively small coverage of the study area by the 12 available meteorological stations and the absence of data from locations with high altitudes (only the Polygyros station is above $250 \mathrm{~m}$ ) impose the need of complementary information to support the relation between temperature, relative humidity, and wind speed and the altitude to make the applied analytical method more efficient. The auxiliary data were the altitudes of 584 independent fire events observed in August in the CM/EMT area from 1984 to 1997, corresponding to altitudes between 0 and $2000 \mathrm{~m}$, so that a complementary database was used to assist mrFFWI data and simulate their variation from place to place with a much smaller statistical error. The result is a very detailed and coherent description of the mrFFWI corresponding to a forest-fire risk assessment for the first time over the CM/EMT area; this index may be used for many environmental purposes such as estimation of fire danger, water-resource management, and energy-saving policies. 
TABLE 2: Monthly values of average $T_{\max }\left({ }^{\circ} \mathrm{C}\right)$ for the HNMS stations in the CM/EMT region during the period 1975-1997.

\begin{tabular}{lcccccc}
\hline Station ID & May & June & July & August & September & October \\
\hline E1 & 22.5 & 27.3 & 30.4 & 30.6 & 26.3 & 20.4 \\
E2 & 22.9 & 27.7 & 30.2 & 30.3 & 26.3 & 20.7 \\
E3 & 23.4 & 28.9 & 30.5 & 29.5 & 26.2 & 20.4 \\
E4 & 24.0 & 28.7 & 31.3 & 30.9 & 27.1 & 21.4 \\
E5 & 24.6 & 29.4 & 31.7 & 31.4 & 27.1 & 21.2 \\
E6 & 25.2 & 29.9 & 31.9 & 31.1 & 28.0 & 21.3 \\
E7 & 23.0 & 28.3 & 29.8 & 29.4 & 25.9 & 20.0 \\
E8 & 21.1 & 26.8 & 29.7 & 29.5 & 25.9 & 20.9 \\
E9 & 22.5 & 27.1 & 29.8 & 29.8 & 25.9 & 20.1 \\
E10 & 25.3 & 29.9 & 32.1 & 31.6 & 28.0 & 21.2 \\
E11 & 20.6 & 26.0 & 27.5 & 27.1 & 24.8 & 19.7 \\
E12 & 25.1 & 29.5 & 31.3 & 30.9 & 27.8 & 21.6 \\
\hline
\end{tabular}

TABLE 3: As Table 2, but of average $\mathrm{RH}_{\text {min }}(\%)$.

\begin{tabular}{lcccccc}
\hline Station ID & May & June & July & August & September & October \\
\hline E1 & 31.1 & 27.9 & 25.0 & 26.6 & 26.5 & 29.2 \\
E2 & 31.9 & 25.5 & 27.3 & 24.6 & 26.6 & 27.4 \\
E3 & 48.0 & 40.5 & 37.2 & 39.7 & 44.4 & 47.6 \\
E4 & 31.9 & 29.3 & 26.1 & 28.1 & 29.4 & 35.6 \\
E5 & 45.2 & 38.2 & 36.4 & 37.9 & 43.7 & 54.9 \\
E6 & 42.8 & 38.8 & 38.6 & 38.8 & 42.7 & 51.7 \\
E7 & 54.3 & 46.9 & 44.9 & 48.6 & 53.1 & 62 \\
E8 & 45.1 & 45.6 & 49.7 & 51.4 & 47.9 & 44.3 \\
E9 & 50.1 & 47.8 & 42.6 & 42.4 & 46.8 & 54.2 \\
E10 & 45.2 & 39.1 & 36.9 & 38.2 & 42.8 & 54.2 \\
E11 & 59.1 & 53.5 & 51.6 & 53.8 & 54.7 & 62.6 \\
E12 & 42.5 & 36.9 & 38.6 & 41.2 & 44.2 & 53.7 \\
\hline
\end{tabular}

\section{Results and Discussion}

For the 12 major cities of CM/EMT (\#E1 to \#E12 in Table 1), the average values for each month of the period under investigation are given in Table 2 for $T_{\max }$, in Table 3 for $\mathrm{RH}_{\text {min }}$, and in Table 4 for WS. By processing these data, the monthly rFFWI values are derived, which are also given in Table 5 for stations \#E1 to \#E12, together with the calculated mrFFWI values. By applying the Kriging analysis to these data, a full set of mrFFWI maps were derived for the CM/EMT region.

By taking into consideration the real fire events observed from NFA in the period 1984-1997 and their distribution to each CM/EMT Prefecture, the corresponding monthly maps for the ratio (burned area/forest coverage area) from May to October are presented in Figures 2-7, respectively. From these figures one can see a gradually increasing ratio of burned area in the hottest months of July, August, and September, while the highest ratios occur in the central (near Kavala Prefecture) and eastern region of CM/EMT (near Kilkis Prefecture), which may be explained from the relatively higher danger of fire near Chrysoupoli (\#E9) on one hand, as this will be demonstrated later in this section
TABLE 4: As Table 2, but of average WS $\left(\mathrm{ms}^{-1}\right)$.

\begin{tabular}{lcccccc}
\hline Station ID & May & June & July & August & September & October \\
\hline E1 & 2.8 & 2.8 & 3.4 & 3.5 & 3.4 & 3.8 \\
E2 & 2.6 & 2.7 & 3.2 & 3.4 & 3.2 & 3.3 \\
E3 & 1.8 & 2.0 & 2.1 & 2.1 & 1.9 & 1.8 \\
E4 & 0.5 & 0.5 & 0.5 & 0.5 & 0.5 & 0.7 \\
E5 & 2.6 & 3.1 & 3.3 & 2.9 & 2.8 & 2.5 \\
E6 & 0.8 & 0.8 & 0.7 & 0.6 & 0.6 & 0.6 \\
E7 & 1.6 & 1.7 & 1.7 & 1.5 & 1.4 & 1.5 \\
E8 & 2.0 & 1.4 & 1.3 & 1.5 & 1.4 & 2.3 \\
E9 & 2.6 & 2.2 & 1.9 & 2.0 & 1.9 & 2.1 \\
E10 & 1.9 & 2.2 & 2.0 & 1.7 & 1.6 & 1.1 \\
E11 & 1.7 & 1.5 & 1.6 & 1.6 & 1.3 & 2.1 \\
E12 & 2.4 & 2.2 & 1.7 & 1.6 & 1.7 & 1.3 \\
\hline
\end{tabular}

with the mrFFWI maps, and from the relatively small forest coverage of the Kilkis Prefecture (33.2\%, Table 1). In Figures 8 and 9 the mrFFWI maps for August and October are shown, respectively; these are constructed by applying the Cokriging analysis (described in the previous section) to the calculated mrFFWI values in Table 5 . In these maps the applied fire-danger level, considering both the meteorological parameters of $T_{\max }, \mathrm{RH}_{\min }$, and WS and the local forestcoverage factor as an indicator of enhanced probability for fire, is represented by gradually changing colored zones; that is, lower mrFFWI values (and thus lower risk of fire) are represented by green color and higher mrFFWI values by red color. In each mrFFWI map the total fire events from 1984 to 1997 are also included, which are represented as dark points with a size proportional to the burned area (in ha).

Monthly average maximum temperature in CM/EMT (see Table 2) is higher in July and August and lower in October at all 12 locations, as expected, while the average minimum relative humidity (see Table 3 ) has an almost opposite behavior, with the higher values occurring in May and October and the lower in July and August. Also, there are many variations in $\mathrm{RH}$ from place to place, depending on various environmental factors, such as the altitude, the forest coverage, and the presence of sea, resulting in differences between the maximum and the minimum $\mathrm{RH}$ values by more than $30 \%$. For the wind speed, the corresponding data of Table 4 show an almost uniform pattern from May to October for all locations, while the minimum WS values reach an average of $0.5 \mathrm{~ms}^{-1}$ at Xanthi (\#E4) and Drama (\#E6) and a maximum of $3.5 \mathrm{~ms}^{-1}$ at Alexandroupoli (\#E1) and $3 \mathrm{~ms}^{-1}$ at Komotini (\#E2) and Thessaloniki (\#E5).

Despite the generally low wind-speed values, as seen above, the dependence of FFWI is much stronger on this parameter than on relative humidity and temperature (the variation of FFWI is about $90 \%$ of that of WS for WS values of $2 \mathrm{~ms}^{-1}$, while the variation of FFWI is less than $4 \%$ of that of $\mathrm{RH}$ and about $0.1 \%$ of that of $T$ for $\mathrm{RH}$ values of the order of $40 \%$ and $T$ values of the order of $25^{\circ} \mathrm{C}$, resp.); therefore, even a small change in WS reflects a greater deviation of FFWI. For this reason, the monthly mrFFWI, as presented in Figures 8 and 9 for August and October, respectively, follows 
TABLE 5: The calculated average rFFWI and mrFFWI values at the HNMS stations in the CM/EMT region during the period $1984-1997$.

\begin{tabular}{|c|c|c|c|c|c|c|c|c|c|c|c|c|}
\hline \multirow{2}{*}{ Station ID } & \multicolumn{2}{|c|}{ May } & \multicolumn{2}{|c|}{ June } & \multicolumn{2}{|c|}{ July } & \multicolumn{2}{|c|}{ August } & \multicolumn{2}{|c|}{ September } & \multicolumn{2}{|c|}{ October } \\
\hline & rFFWI & mrFFWI & rFFWI & mrFFWI & rFFWI & mrFFWI & rFFWI & mrFFWI & rFFWI & mrFFWI & rFFWI & mrFFWI \\
\hline E1 & 13.8 & 15.3 & 14.3 & 15.8 & 17.9 & 19.8 & 18.4 & 20.4 & 17.5 & 19.4 & 18.7 & 20.8 \\
\hline E2 & 12.5 & 19.0 & 14.5 & 22.1 & 16.4 & 24.9 & 18.2 & 27.6 & 16.8 & 25.5 & 16.8 & 25.4 \\
\hline E3 & 7.2 & 8.0 & 8.9 & 9.9 & 9.9 & 11.0 & 9.5 & 10.5 & 7.9 & 8.8 & 7.1 & 7.9 \\
\hline $\mathrm{E} 4$ & 3.1 & 6.1 & 3.4 & 6.8 & 3.5 & 7.0 & 3.3 & 6.6 & 3.3 & 6.6 & 3.9 & 7.9 \\
\hline E5 & 10.8 & 10.8 & 14.2 & 14.2 & 15.5 & 15.5 & 13.4 & 13.4 & 11.8 & 11.8 & 9.2 & 9.2 \\
\hline E6 & 4.0 & 8.4 & 4.0 & 8.5 & 3.6 & 7.7 & 3.4 & 7.3 & 3.2 & 6.9 & 2.8 & 6.0 \\
\hline E7 & 6.2 & 9.3 & 7.3 & 11.0 & 7.3 & 11.0 & 6.4 & 9.6 & 5.6 & 8.4 & 5.1 & 7.7 \\
\hline E8 & 8.2 & 15.7 & 6.2 & 11.9 & 5.5 & 10.6 & 6.1 & 11.6 & 5.8 & 11.1 & 9.7 & 18.6 \\
\hline E9 & 9.7 & 18.7 & 8.8 & 16.9 & 8.4 & 16.1 & 8.6 & 16.5 & 7.9 & 15.1 & 7.6 & 14.6 \\
\hline E10 & 8.0 & 9.6 & 10.1 & 12.1 & 9.5 & 11.3 & 8.2 & 9.8 & 7.0 & 8.4 & 4.4 & 5.3 \\
\hline E11 & 6.2 & 12.6 & 5.9 & 12.0 & 6.4 & 13.0 & 6.1 & 12.4 & 5.1 & 10.4 & 7.0 & 14.3 \\
\hline E12 & 10.4 & 11.9 & 10.3 & 11.8 & 8.1 & 9.3 & 7.4 & 8.5 & 7.3 & 8.4 & 5.1 & 5.9 \\
\hline
\end{tabular}

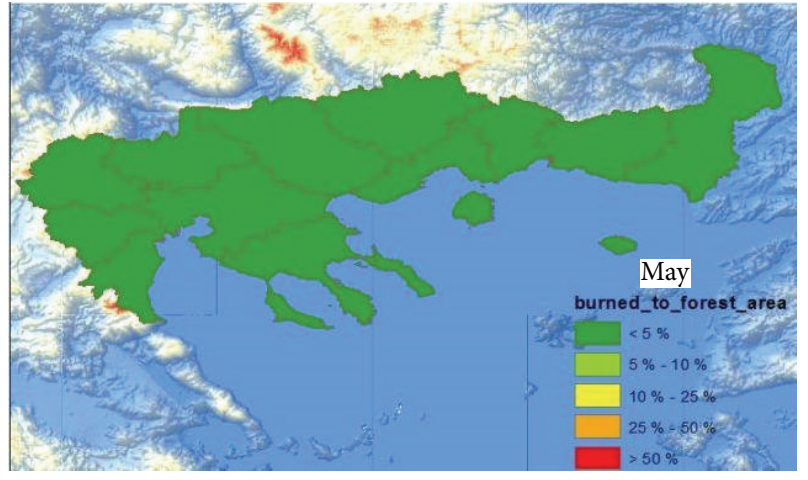

FIGURE 2: The distribution of the average ratio of the burned area (in ha) to the forest coverage (in ha) for the Prefectures of the CM/EMT area during May in the period 1984-1997.

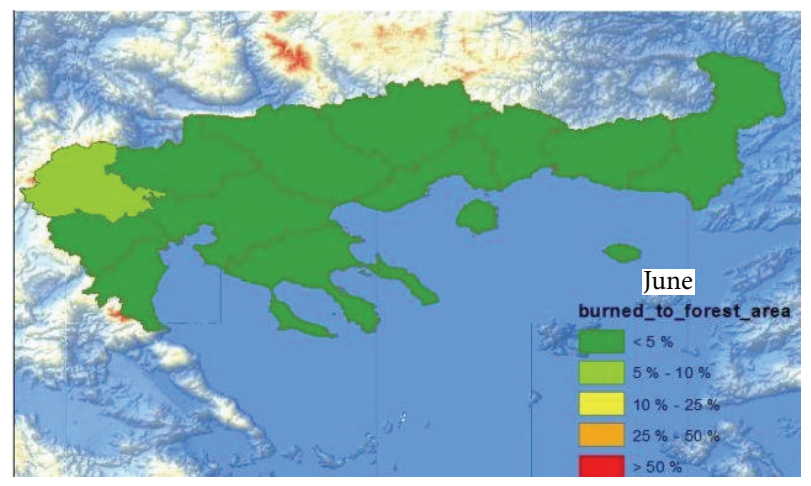

FIgURE 3: As in Figure 2, but during June.

almost identically the spatial distribution of wind speed. The estimation for possible fire generation is good for the center of the CM/EMT area, since there is an agreement between the patterns of the mrFFWI and the burned areas, especially around Kavala and Chalkidiki where the higher risk-of-fire is estimated for both months. On the other hand, the mrFFWI is overestimated in Thrace (around Xanthi and Rodopi),

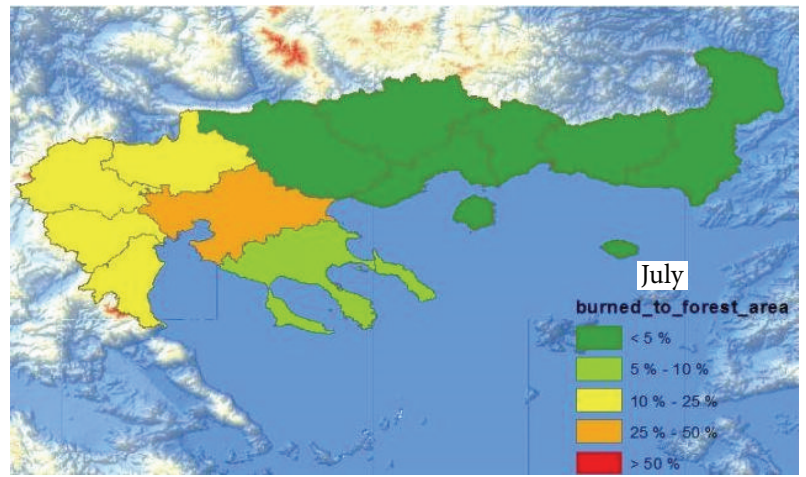

FIGURE 4: As in Figure 2, but during July.

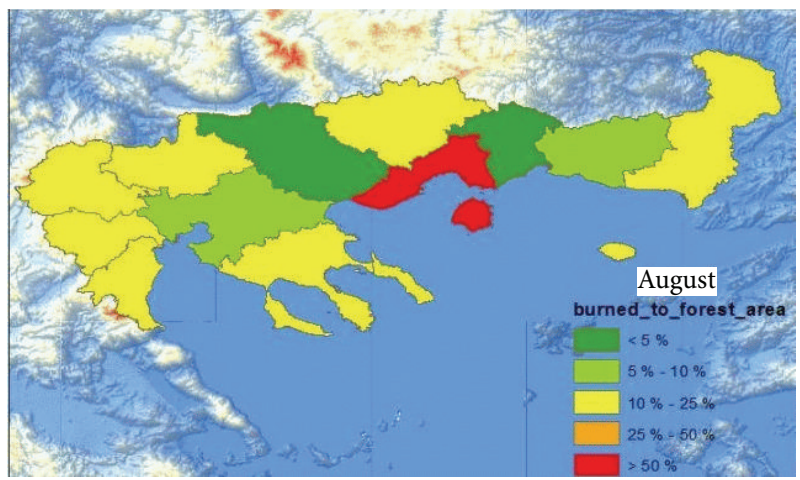

Figure 5: As in Figure 2, but during August.

due to the higher wind speeds observed which increase the original FFWI, although the ratio of the burned area to the forest coverage is small. Due to the lower wind speeds in Central Macedonia (around Kilkis and Pella Prefectures) the mrFFWI is underestimated.

From Figures 8 and 9 the most frequent fire incidents are observed to be in the central region of the maps near Kavala and Chalkidiki for August, as it is predicted from the corresponding mrFFWI values, while in October the fire 


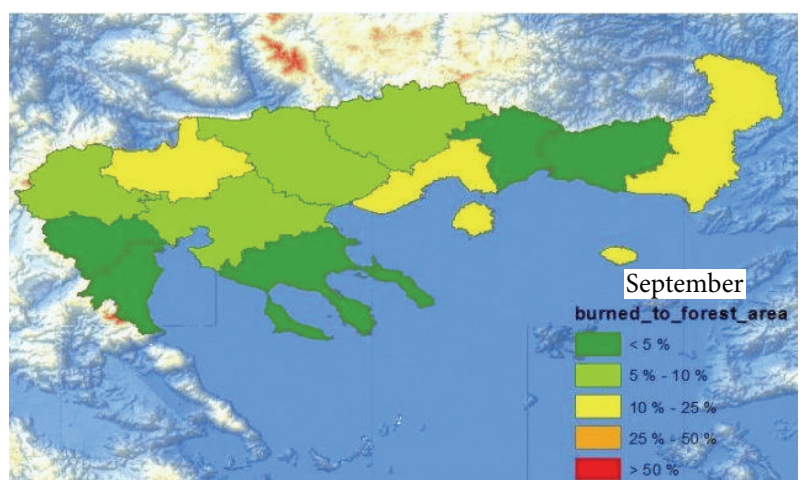

FIgURE 6: As in Figure 2, but during September.

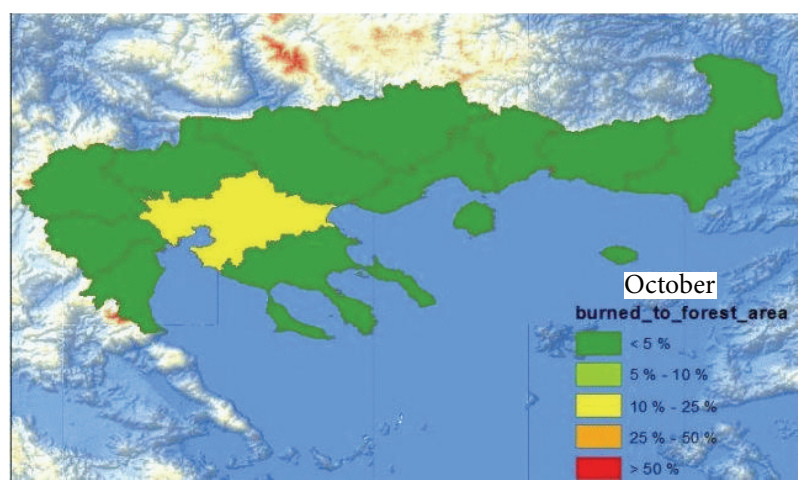

FIgURE 7: As in Figure 2, but during October.

incidents are fewer, as expected, and most of them occur in the central part of the CM/EMT region. Since mrFFWI in the western part of the CM/EMT area is relatively small for both months (less than 10), a possible explanation is that many of these fire events have occurred due to anthropogenic factors rather than due to the effect of the environment, as it is generally accepted [28].

Following the categorization of the fire-danger level corresponding to the mrFFWI value as it has been mentioned above, we see from Table 5 that for the whole period under investigation and in the majority of the locations the firedanger level is low, except at Komotini station (\#E2) from June to October and at Alexandroupoli station (\#E1) for August and October where the fire-danger level is moderate $(\mathrm{mrFFWI}>20)$. These exceptions occur due to the prevailing high wind speeds and do not affect the general conclusion that there is a low fire-risk level for the region of CM/EMT, a reasonable result taking into consideration the generally cooler climatic conditions and weaker wind speeds that are observed in these areas of Greece.

\section{Conclusions}

The Fosberg Fire-Weather Index (FFWI) was used in Northern Greece, specifically in the regions of Central Macedonia, Eastern Macedonia, and Thrace (CM/EMT), to assess the fire risk. Instead of utilizing the daily average value of the

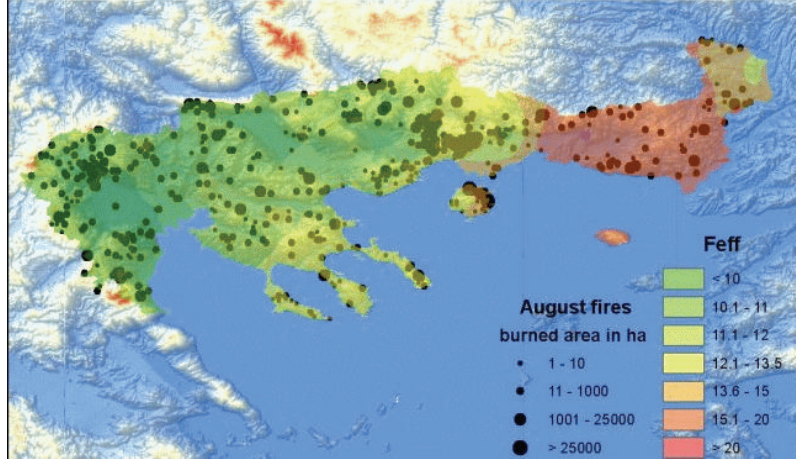

FIGURE 8: The mrFFWI $\left(F_{\text {eff }}\right)$ map for the determination of the fire danger over the CM/EMT area for August. Red colored areas correspond to moderate danger level $\left(F_{\text {eff }}>20\right)$, while the rest of colors correspond to low danger. The dots correspond to the fire events observed in the period 1984-1997 for the same month (a total number of 608) and their size is proportional to the area burned (in ha) per incident (the greater area burned was 10,4000 ha and took place in 1985 in the island of Thasos, Kavala Prefecture).

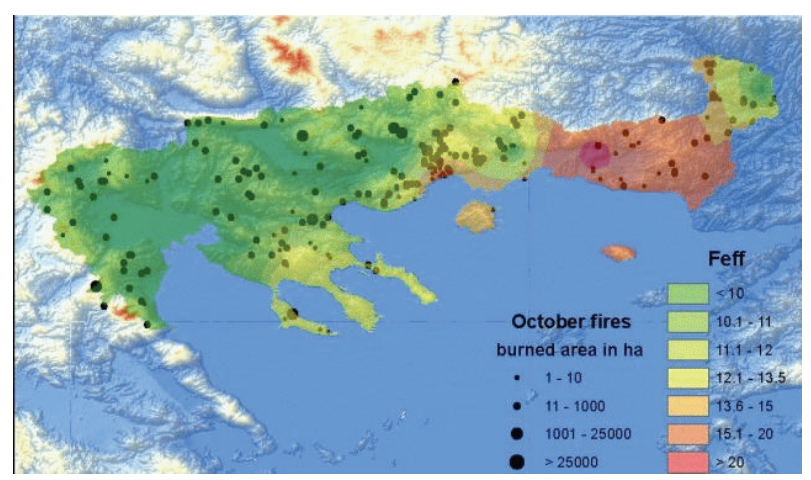

FIGURE 9: The mrFFWI $\left(F_{\text {eff }}\right)$ map for the determination of the fire danger over the CM/EMT area for October. Red colored areas correspond to moderate danger level $\left(F_{\text {eff }}>20\right)$, while the rest of colors correspond to low danger. The dots correspond to the fire events observed in the period 1984-1997 for the same month (a total number of 68) and their size is proportional to the area burned (in ha) per incident (the greater area burned was 1,580 ha).

air temperature in the original FFWI, use of the rFFWI was made that includes the daily maximum value of air temperature $\left(T_{\max }\right)$ and daily minimum value of relative humidity $\left(\mathrm{RH}_{\min }\right)$. A further modification to the rFFWI was introduced in the present work, mrFFWI, to include the forest coverage in each area studied; this modification was presented for the first time.

Based on monthly means of meteorological data $\left(T_{\max }, \mathrm{RH}_{\min }\right)$ from various stations of the NHMS network in the CM/EMT region, fire-risk maps presenting the ratio of the burned area to the forest coverage in the CM/EMT area were derived for each month of the fire-risk period (May to October) by using mrFFWI and the Kriging geospatial method.

A comparison of the derived mrFFWI values for the $\mathrm{CM} / \mathrm{EMT}$ region was made against real-fire events recorded 
in the period 1984-1997 by NFA. The comparison showed an agreement between the mrFFWI value and the corresponding burned area.

Low fire danger was found at Komotini (low values of $\mathrm{mrFFWI}$ ) and moderate ones were at Alexandroupoli (moderate values of mrFFWI).

\section{Disclosure}

George K. Kalliampakos is on provisional assignment to the Hellenic Parliament.

\section{Competing Interests}

The authors declare that there is no conflict of interests regarding the publication of this paper.

\section{Acknowledgments}

The authors would like to thank the HNMS for the availability of the necessary meteorological data and the NFA for the disposition of the fire-events database.

\section{References}

[1] I. Matyasovszky, I. Bogardi, and J. Ganoulis, "Impact of global climate change on temperature and precipitation in Greece," Applied Mathematics and Computation, vol. 71, no. 2-3, pp. 119150, 1995.

[2] K. Tolika, C. Anagnostopoulou, P. Maheras, and M. Vafiadis, "Simulation of future changes in extreme rainfall and temperature conditions over the Greek area: a comparison of two statistical downscaling approaches," Global and Planetary Change, vol. 63, no. 2-3, pp. 132-151, 2008.

[3] P. Zanis, I. Kapsomenakis, C. Philandras et al., "Analysis of an ensemble of present day and future regional climate simulations for Greece," International Journal of Climatology, vol. 29, no. 11, pp. 1614-1633, 2009.

[4] H. D. Kambezidis and G. Kalliampakos, "Mapping atmospheric corrosion on materials of archaeological importance in Athens," Water, Air, and Soil Pollution, vol. 223, no. 5, pp. 2169-2180, 2012.

[5] B. D. Katsoulis and H. D. Kambetzidis, "Analysis of the longterm precipitation series at Athens, Greece," Climatic Change, vol. 14, no. 3, pp. 263-290, 1989.

[6] D. Founda, K. H. Papadopoulos, M. Petrakis, C. Giannakopoulos, and P. Good, "Analysis of mean, maximum, and minimum temperature in Athens from 1897 to 2001 with emphasis on the last decade: trends, warm events, and cold events," Global and Planetary Change, vol. 44, no. 1-4, pp. 27-38, 2004.

[7] D. Efthymiadis, C. M. Goodess, and P. D. Jones, "Trends in Mediterranean gridded temperature extremes and largescale circulation influences," Natural Hazards and Earth System Science, vol. 11, no. 8, pp. 2199-2214, 2011.

[8] M. A. Gouvas, N. K. Sakellariou, and H. D. Kambezidis, "Estimation of the monthly and annual mean maximum and mean minimum air temperature values in Greece," Meteorology and Atmospheric Physics, vol. 110, no. 3, pp. 143-149, 2011.

[9] E. Kostopoulou, K. Tolika, I. Tegoulias et al., "Evaluation of a regional climate model using in situ temperature observations over the Balkan Peninsula," Tellus, Series A: Dynamic Meteorology and Oceanography, vol. 61, no. 3, pp. 357-370, 2009.

[10] E. E. Houssos and A. Bartzokas, "Extreme precipitation events in NW Greece," Advances in Geosciences, vol. 7, pp. 91-96, 2006.

[11] H. D. Kambezidis, I. K. Larissi, P. T. Nastos, and A. G. Paliatsos, "Spatial variability and trends of the rain intensity over Greece," Advances in Geosciences, vol. 26, pp. 65-69, 2010.

[12] I. Kioutsioukis, S. Rapsomanikis, and R. Loupa, "Robust stochastic seasonal precipitation scenarios," International Journal of Climatology, vol. 26, no. 14, pp. 2077-2095, 2006.

[13] TEE, "Climate data of Greek regions," Technical Guide 20701, Ministry of Environment, Energy and Climatic Change, 2010.

[14] A. Camia and G. Bovio, "Description of the EUDIC software for fire danger indices calculation," in Final Report to JRC on "Computation of Meteorological Fire Danger Indices for Southern Europe”, p. 14, 2000.

[15] J. A. Dowdy, G. A. Mills, A. Finkele, and W. de Groot, "Australian fire weather as represented by the McArthur FFDI and the Canadian Forest FWI," CAWCR Technical Report no. 10, 2009.

[16] D. A. Haines, W. A. Main, J. S. Frost, and A. J. Simard, "Firedanger rating and wildfire occurrence in the northeastern United States," Forest Science, vol. 29, no. 4, pp. 679-696, 1983.

[17] C. E. van Wagner and T. L. Pickett, "Equations and FORTRAN program for the Canadian forest fire weather index system, canadian forestry service," Tech. Rep. 33, 1985.

[18] I. R. Noble, A. M. Gill, and G. A. Bary, "McArthur's fire-danger meters expressed as equations," Austral Ecology, vol. 5, no. 2, pp. 201-203, 1980.

[19] J. J. Sharples, R. H. D. McRae, R. O. Weber, and A. M. Gill, "A simple index for assessing fire danger rating," Environmental Modelling and Software, vol. 24, no. 6, pp. 764-774, 2009.

[20] L. Bradshaw, J. E. Deeming, R. E. Burgan, and J. D. Cohen, "The national fire danger rating system," USDA Forest Service, General Technical Report INT, 1977.

[21] J. O. Roads, K. Ueyoshi, S. C. Chen, J. Alpert, and F. Fujioka, "Medium-range fire weather forecasts," International Journal of Wildland Fire, vol. 1, no. 3, pp. 159-176, 1991.

[22] M. A. Fosberg, "Weather in wildland fire management: the fire weather index," in Proceedings of the Conference on Sierra Nevada Meteorology, pp. 1-4, South Lake Tahoe, Calif, USA, June 1978.

[23] H. K. Preisler, S.-C. Chen, F. Fujioka, J. W. Benoit, and A. L. Westerling, "Wildland fire probabilities estimated from weather model-deduced monthly mean fire danger indices," International Journal of Wildland Fire, vol. 17, no. 3, pp. 305-316, 2008 .

[24] J. O. Roads, S. C. Chen, J. Ritchie, F. Fujioka, H. Juang, and M. Kanamitsu, "ECPC's global to regional fire weather forecast system," in Early Warning Systems for Natural Disaster Reduction, part 4, pp. 609-613, 2003.

[25] S. Matthews, "A comparison of fire danger rating systems for use in forests," Australian Meteorological and Oceanographic Journal, vol. 58, no. 1, pp. 41-48, 2009.

[26] S. L. Goodrick, "Modification of the Fosberg fire weather index to include drought," International Journal of Wildland Fire, vol. 11, no. 3-4, pp. 205-211, 2002. 
[27] P. A. Burrough and R. A. McDonnell, Principles of Geographical Information Systems, Oxford University Press, New York, NY, USA, 1998.

[28] J. Martínez-Fernández, E. Chuvieco, and N. Koutsias, "Modelling long-term fire occurrence factors in Spain by accounting for local variations with geographically weighted regression," Natural Hazards and Earth System Science, vol. 13, no. 2, pp. 311327, 2013. 

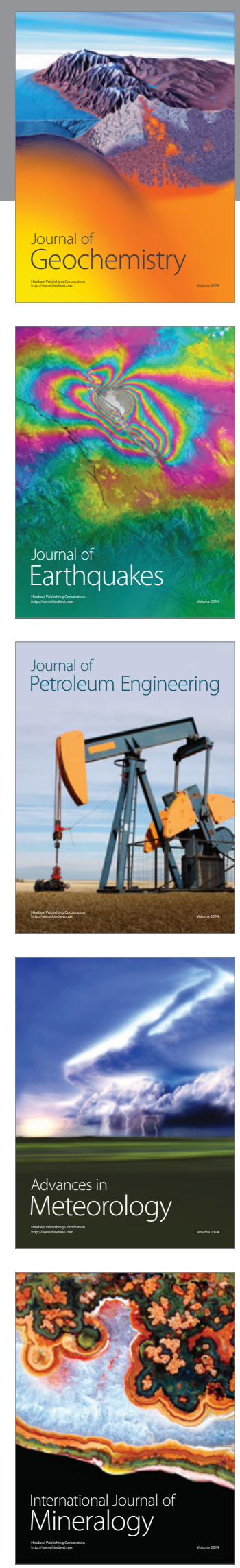
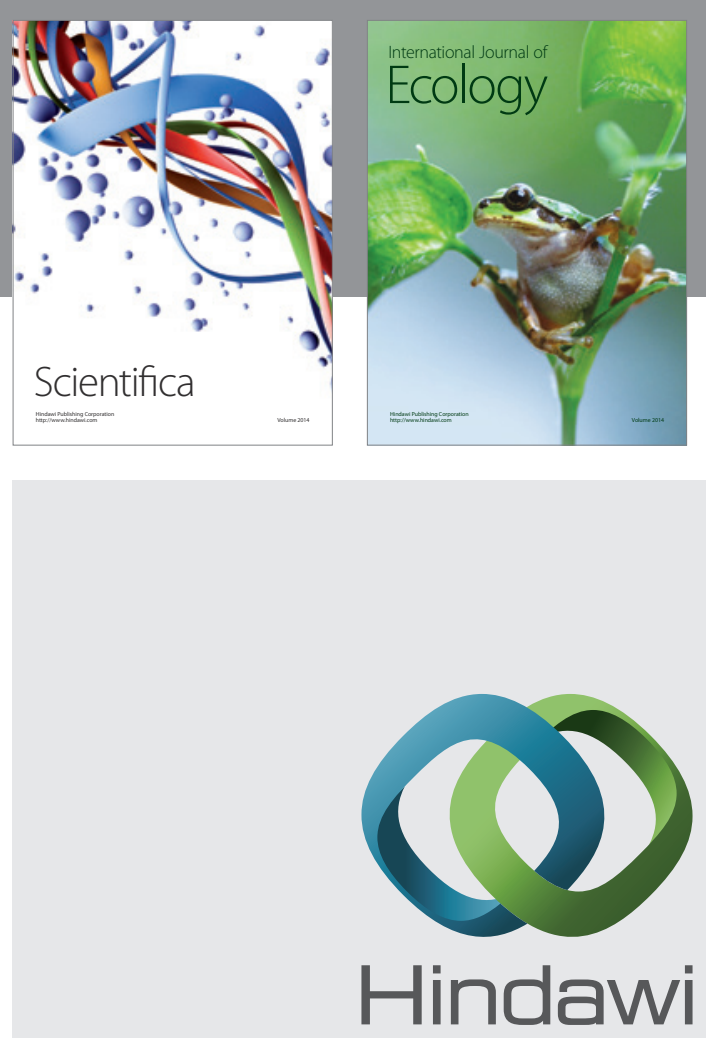

Submit your manuscripts at

http://www.hindawi.com
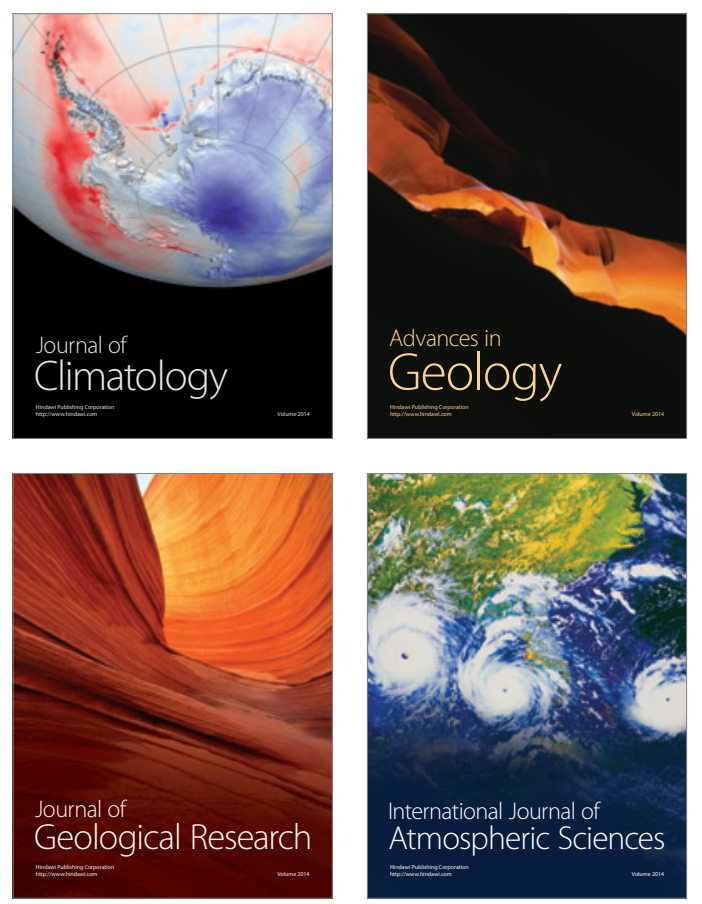

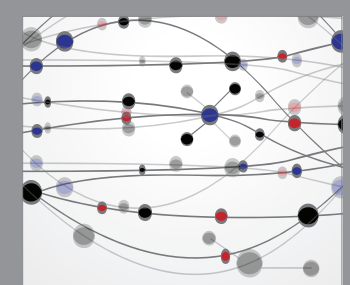

The Scientific

\section{World Journal}
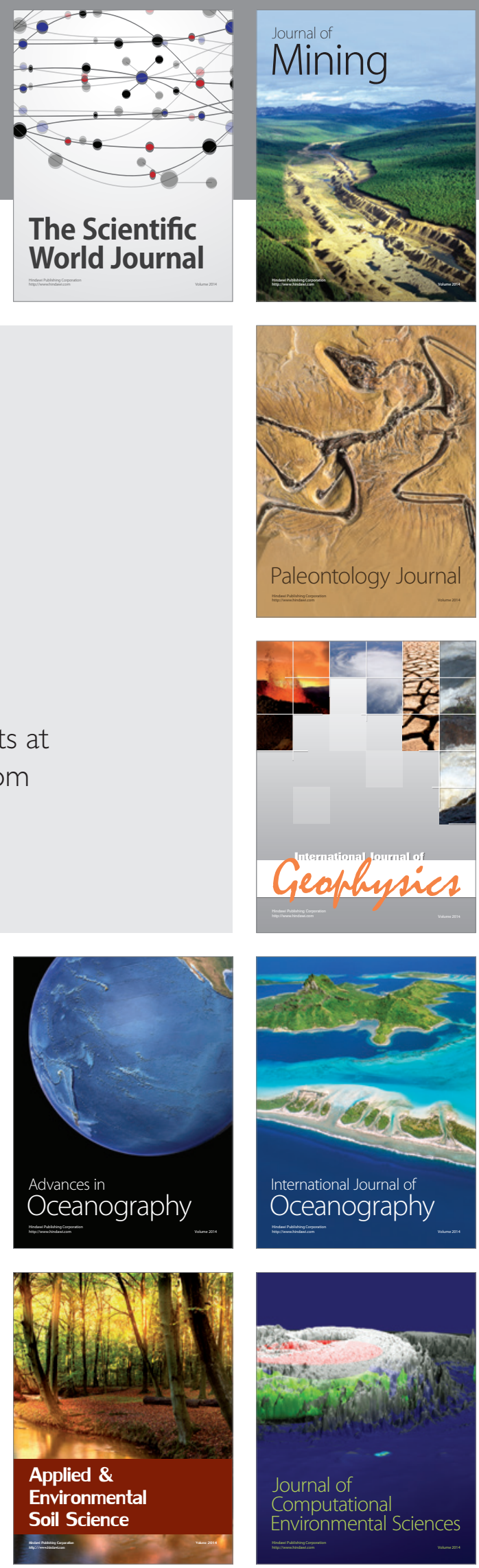